\title{
Continuous-flow left ventricular assist device implantation in the presence of a hostile ventricular apex
}

\author{
Pavan Atluri, MD, Daniel J. Dymond, PA-C, and Y. Joseph Woo, MD, Philadelphia, Pa
}

\begin{abstract}
Management of a patient with a hostile ventricular apex at the time of continuous flow left ventricular assist device (LVAD) implantation is a challenging problem. Patients with ventricular apical aneurysm, calcified left ventricular apex, large mural thrombus burden, or massive apical myocardial infarction with friable myocardium may be unsuited to traditional LVAD implant techniques. The survival of these patients relies on the implantation of the LVAD with good inflow cannula positioning in the left ventricle. We describe a novel implant technique for a HeartMate II LVAD (Thoratec Corp, Pleasanton, Calif) in a patient with a heavily calcified left ventricular apex.
\end{abstract}

From the Division of Cardiovascular Surgery, Department of Surgery, Perelman School of Medicine, University of Pennsylvania, Philadelphia, Pa.

Disclosures: Authors have nothing to disclose with regard to commercial support.

Received for publication Jan 6, 2012; accepted for publication Jan 16, 2012; available ahead of print Aug 15, 2013.

Address for reprints: Y. Joseph Woo, MD, Division of Cardiovascular Surgery, Department of Surgery, University of Pennsylvania, Silverstein 6, 3400 Spruce

St, Philadelphia, PA 19104 (E-mail: wooy@uphs.upenn.edu).

J Thorac Cardiovasc Surg 2013;146:981-2

$0022-5223 / \$ 36.00$

Copyright (c) 2013 by The American Association for Thoracic Surgery

http://dx.doi.org/10.1016/j.jtcvs.2012.01.090

\section{OPERATIVE TECHNIQUE}

A 66-year-old woman had sustained a proximal left anterior descending coronary infarct in 2002. Multiple percutaneous coronary interventions were performed without revascularization of the anterior left ventricular wall. During the ensuing years, ischemic cardiomyopathy developed, with marked hemodynamic compromise (ejection fraction $15 \%)$ and significant limitation of the patient's activities (New York Heart Association class IV heart failure).

After a sternotomy, it was evident that a large portion of the left ventricle and apex was heavily calcified. Transesophageal echocardiography demonstrated a large amount of thrombus within the ventricular cavity. With care taken to avoid manipulation of the ventricle and thus risk embolism, the patient was placed on cardiopulmonary bypass with standard ascending aortic arterial and right atrial dualstage venous cannulation. The apex was then exposed, and a ventriculotomy was made. The myocardium was very calcified and friable. It was judged that sutures could not be placed with adequate hemostasis. In addition, adequate débridement of the apical thrombus could not be performed through the limited ventriculotomy, thereby increasing stroke risk. At this stage, the decision was made to excise the entire ventricular anteroapex and
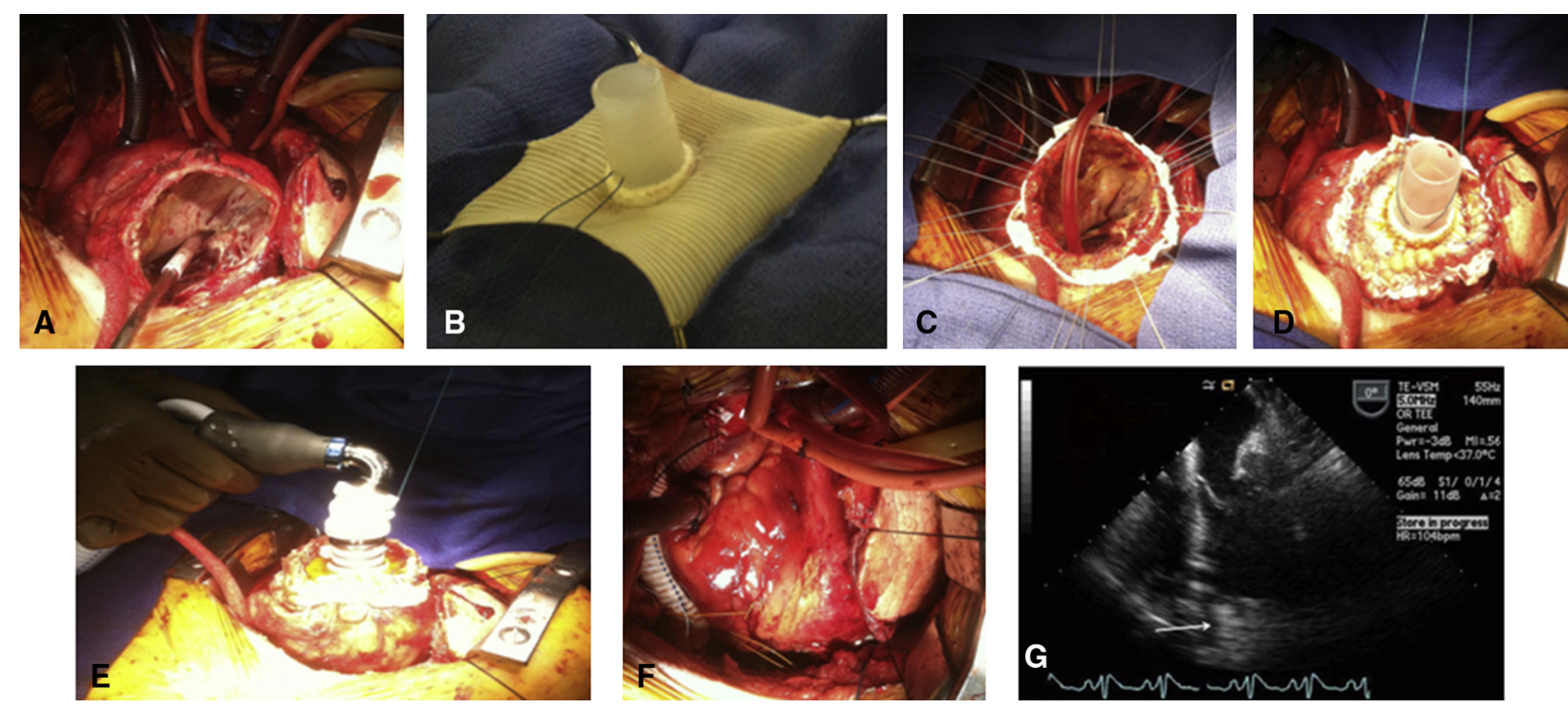

FIGURE 1. A, Extensive ventriculotomy and débridement of thrombus from the endocardial surface. B, Inflow cannula graft that was constructed with a Dacron polyester fabric graft and standard HeartMate II inflow cannula. C, Standard placement of circumferential polytetrafluoroethylene pledgeted sutures around the ventriculotomy. D, Inflow cannula graft secured to the neoventricular apex. E, Standard insertion of the HeartMate II left ventricular assist device. F, Intraoperative image after outflow anastomosis to the ascending aorta. G, Intraoperative transesophageal echocardiogram demonstrating optimal position of the inflow cannula (arrow). 


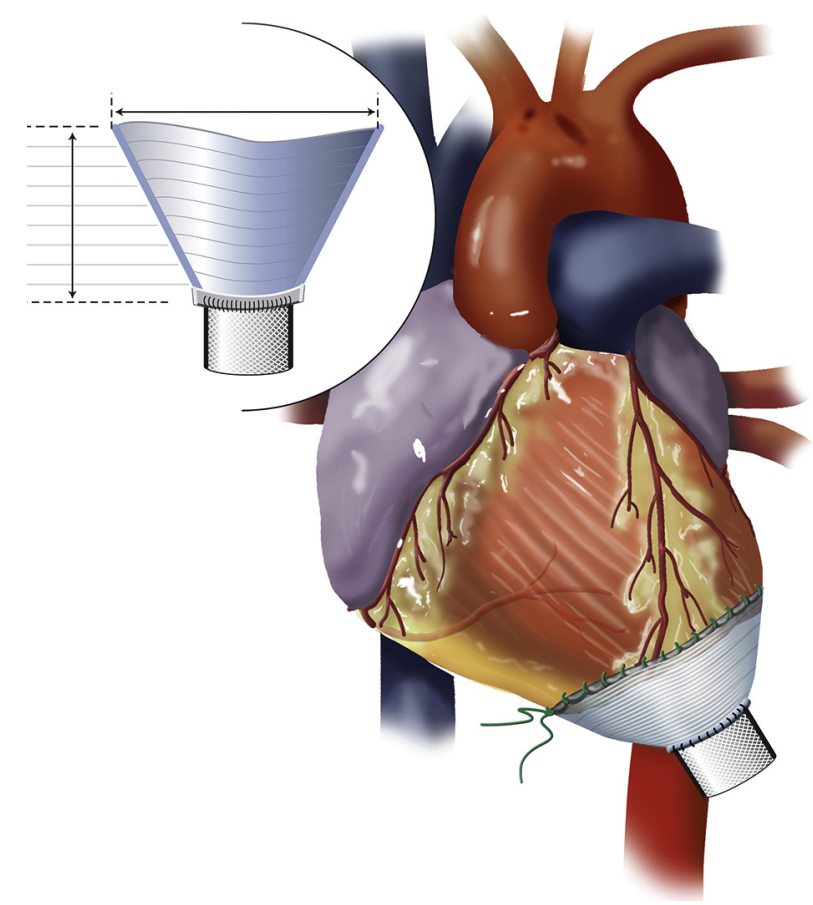

FIGURE 2. Artist's rendering of a potentially closer to optimal conical Dacron polyester fabric graft to facilitate HeartMate II left ventricular assist device implantation after left ventricular apical resection.

thoroughly débride all thrombus from the left ventricular cavity (Figure 1). Next, an inflow cannula graft was fashioned from the standard HeartMate II inflow cannula and a Dacron polyester fabric graft. The graft was sized to the diameter of the ventriculotomy. A hole the diameter of the inflow cannula was made in the center of the graft, and the standard HeartMate II cannula was inserted from the ventricular surface of the Dacron graft. This cannula was secured to the Dacron graft with a running 4-0 Prolene (Ethicon, Inc, Somerville, NJ) suture line. Standard interrupted, pledgeted 2-0 Tevdek (Teleflex Incorporated, Research Triangle Park, NC) sutures were placed circumferentially from the epicardium to endocardium. The sutures were then passed through the Dacron graft circumferentially, from the ventricular surface, and tied. The myocardial graft interface was secured with biologic glue. At this stage, the HeartMate II LVAD cannula was inserted and secured in standard fashion. Intraoperative transesophageal echocardiography demonstrated good positioning of the inflow cannula.

The patient had an uneventful postoperative recovery and was discharged to rehabilitation without incident. Standard anticoagulation with $81 \mathrm{mg}$ aspirin and warfarin sodium (goal international normalized ratio of 1.8-2.5) was instituted. The patient did not have any neurologic events. She is doing very well without adverse events or pumprelated issues 7 months after the implantation.

\section{DISCUSSION}

The presence of a hostile ventricular apex should not prevent implantation of a continuous-flow LVAD. The novel technique described here provides the capacity to implant a HeartMate II LVAD in nontraditional situations in which a significant ventriculotomy may be needed for either management of the apex or exposure to the ventricular cavity. Specific uses for this graft include left ventricular aneurysm, massive thrombus requiring a larger than normal exposure to evacuate the ventricle, previous left ventricular aneurysm surgery, massive acute infarct with a necrotic apex, post-myocardial infarction ventricular septal defect, a thin apex with concern for the ability to obtain hemostasis, a calcified apex (as in this case), previous transapical surgery, previous LVAD, and conversion from a Thoratec paracorporeal ventricular assist device to HeartMate II LVAD. We have previously published our results with apical inflow cannulation after an acute myocardial infarction. Although this can be safely performed, it may be optimal to resect nonviable, friable myocardium and suture to healthy muscle with a graft as described. ${ }^{1}$ Numerous reports have demonstrated superior hemodynamics with direct ventricular cannulation relative to alternative cannulation strategies, such as atrial cannulation. ${ }^{2-5}$ This technique would be highly applicable to conditions that would have forced a surgeon to consider nonventricular cannulation strategies for a ventricular assist device. An optimized conical Dacron graft prefashioned to the connector would be highly versatile for use in all these scenarios (Figure 2). Because of the fixation of the HeartMate II LVAD in the subrectus, preperitoneal space, the inflow cannula can be optimally positioned without compromised inflow.

\section{References}

1. Leshnower BG, Gleason TG, O'Hara ML, Pochettino A, Woo YJ, Morris RJ, et al. Safety and efficacy of left ventricular assist device support in postmyocardial infarction cardiogenic shock. Ann Thorac Surg. 2006;81:1365-70; discussion 1370-1.

2. Tevaearai HT, Mueller XM, Jegger D, Horisberger J, Von Segesser L. Atrial, ventricular, or both cannulation sites to optimize left ventricular assistance? ASAIO J. 2001;47:261-5.

3. Schlensak C, Schibilsky D, Siepe M, Brehm K, Klemm R, von Wattenwyl R, et al. Biventricular cannulation is superior regarding hemodynamics and organ recovery in patients on biventricular assist device support. J Heart Lung Transplant. 2011; 30:1011-7.

4. Timms D, Gregory S, Hsu PL, Thomson B, Pearcy M, McNeil K, et al. Atrial versus ventricular cannulation for a rotary ventricular assist device. Artif Organs. 2010;34:714-20.

5. Korakianitis T, Shi Y. Numerical comparison of hemodynamics with atrium to aorta and ventricular apex to aorta VAD support. ASAIO J. 2007;53:537-48. 